\title{
Libras e a gestão compartilhada das águas: trocando experiências na produção de vídeos educomunicativos para a comunidade surda
}

Tabita Teixeira

Mestra em Ciências pelo Programa de Pós-Gradução em Rede Nacional para Ensino das Ciências Ambientais da Universidade de São Paulo e Especialista em Educação Ambiental para a Sustentabilidade.

E-mail: tabitateixeira@gmail.com

Fernanda da Rocha Brando Professora Associada do Departamento de Biologia da Faculdade de Filosofia, Ciências e Letras da USP e orientadora do Programa de Pós-graduação em Rede Nacional para Ensino das Ciências Ambientais da mesma instituição.

E-mail: ferbrando@ffclrp.usp.br

Resumo: A exclusão da comunidade surda ocorre, muitas vezes, devido à falta de acessibilidade deste público quanto às informações, ao conhecimento e aos poucos materiais educomunicativos disponíveis gratuitamente. Neste trabalho, o foco recai em materiais que abordam questões socioambientais relacionadas à água. A experiência relatada refere-se à produção de seis vídeos em Libras, sobre a temática água, realizada no segundo semestre de 2018, a partir de um estudo em conjunto com surdos de uma associação. Esses materiais estão disponíveis gratuitamente na Internet e têm como público-alvo indivíduos e comunidades surdas, profissionais e instituições que atuam na área. Espera-se que os vídeos despertem a curiosidade
Abstract: The deaf community is excluded due to the lack of accessibility to information, knowledge and the few educomunication materials concerning water socioenvironmental queries available. Our study shows the production of six Brazilian Sign Language (BSL) videos on water from 2018. The videos were based on studies with the deaf association. The materials are available online and have deaf individuals and communities, professionals and institutions in this area as the main target public. These videos are expected to arouse extra curiosity, awaken sensibility and raise awareness of water issues, also serving as a tool for studies on Environmental Education.
Recebido: 12/11/2019

Aprovado: 20/09/2020 
de seus visualizadores, a sensibilização e conscientização quanto à água e sirvam como ferramenta de estudo para possíveis ações e projetos de Educação Ambiental, promovendo, assim, a gestão compartilhada das águas.

Palavras-chave: surdo; educação ambiental; água; educomunicação; TDIC. projects and actions, thus promoting shared waters management.

Keywords: deaf people; environmental education; water; educommunication; DICT.
1. BRASIL. Lei n 9.433, de 8 de janeiro de 1997 Institui a Política Nacional de Recursos Hídricos, cria o Sistema Nacional de Gerenciamento de Recursos Hídricos, regulamenta o inciso XIX do art. 21 da Constituição Federal, e altera 0 art. $1^{\circ}$ da Le $n^{\circ} 8.001$, de 13 de março de 1990, que modificou a Lei n० 7.990, de 28 de dezembro de 1989. Diário Oficial da União, Brasília, DF, 9 jan. 1997. Disponível em: http://www.planalto.gov.br/ccivil_03/leis/ L9433.htm. Acesso em: 22 nov. 2017.

2. BRASIL. Lei n ${ }^{\circ} 9.795$ de 27 de abril de 1999. Dispõe sobre a educação ambiental institui a Política Nacional de Educação Ambiental e dá outras providências. Diário Oficial da União Brasília, DF, 28 abr. 1999. Disponível em: http://www. planalto.gov.br/ccivil_03/ leis/19795.htm. Acesso em: 20 jan. 2017.

3. Ibidem.

\section{INTRODUÇÃO}

A água é um bem comum e fundamental tanto para a manutenção da vida no planeta quanto para as atividades humanas. Entretanto, as atividades realizadas pelos seres humanos influenciam e impactam negativamente a qualidade e a insuficiência do acesso à água potável por algumas populações, interferindo em seus ciclos, causando poluição e degradando seus ecossistemas. Diante dessas realidades, há a necessidade de discutir e de criar medidas que melhorem o planejamento e o manejo adequado dos recursos hídricos, incluindo uma participação mais ativa da sociedade na gestão das águas.

A Política Nacional de Recursos Hídricos - Lei Federal n 9.43387¹, também conhecida como "Lei das Águas" - tem como base que a gestão da água deve ser descentralizada e participativa, por meio de usuários, da sociedade civil e do governo. Uma das formas que possibilita um indivíduo, grupo e/ ou comunidade a se tornarem mais ativos quanto às questões socioambientais relacionadas à água é a Educação Ambiental.

De acordo com a Política Nacional de Educação Ambiental - Lei Federal $n^{\circ}$ 9.795/1999² - a Educação Ambiental envolve o indivíduo e o coletivo na construção de valores sociais, conhecimentos, habilidades e atitudes voltadas para a conservação e proteção do meio ambiente e da cidadania, sendo essencial e permanente, de forma que deve estar inclusa nos processos educacionais do ensino formal e não formal. Ainda sobre essa lei ${ }^{3}$, além de participativa, a Educação Ambiental deve ser interdisciplinar e transversal, podendo ser trabalhada por todas as faixas etárias, a partir do momento que considere e respeite a realidade, a história e o emocional de cada sujeito, tornando-o um potencial ator/atriz multiplicador e transformador de sua realidade. Esse processo permite despertar a percepção ambiental do indivíduo, sensibilizando-o e conscientizando-o por meio da troca de conhecimentos com o grupo e a promoção de diversas ações, as quais, nesse caso, estão relacionadas à conservação da qualidade e quantidade da água e de seus ecossistemas. Por isso, é importante que as comunidades se envolvam na gestão compartilhada junto aos demais setores, devendo incluir, portanto, nessa somatória, a comunidade surda. 
Para Miorando ${ }^{4}$, devido às lutas históricas e políticas dessas comunidades no país e no mundo, o termo "surdo" trata da identidade e do orgulho desses sujeitos que percebem, sentem e representam o mundo ao seu redor por meio da Língua Brasileira de Sinais (Libras), fazendo parte de sua cultura. Logo, esse será o termo empregado ao longo desse artigo.

A Libras é reconhecida pela Lei Federal $n^{0} 10.436 / 02^{5}$ (regulamentada pelo Decreto $n^{0} 5.626 / 05^{6}$ ) e, de acordo com Sousa ${ }^{7}$, normalmente é a primeira língua aprendida e utilizada por alguns surdos nos centros urbanos, sendo sua segunda língua o Português (leitura e escrita), tornando-os bilíngues. Dessa forma, eles também são multiculturais, uma vez que partilham tanto da diversidade cultural entre os demais surdos quanto da dos ouvintes, sendo que estes possuem a cultura da audição (comunicação por meio da escrita e da oralização). Apesar disso, muitos surdos têm dificuldade em compreender a Língua Portuguesa, bem como de se apropriarem das informações escritas e audíveis ao seu redor.

De acordo com o Estatuto da Pessoa com Deficiência, Lei Federal n ${ }^{\circ} 13.146^{8}$, o surdo também tem direito a acessar tanto a informação quanto a comunicação, devendo ser incentivada a produção e edição de materiais em Libras. Além da democratização das informações, o surdo também tem o direito de frequentar espaços educomunicativos, nos quais se planejam, criam e desenvolvem ecossistemas educativos por meio de processos de comunicação e do uso de tecnologias da informação, como explicado por Soares apud Trajber ${ }^{9}$. Esses espaços educativos (físicos ou virtuais) são abertos, criativos e democráticos, facilitando o processo de ensino-aprendizagem por meio da comunicação entre os grupos, podendo contribuir com a articulação e mobilização entre as comunidades surdas, principalmente quanto à construção de sua relação socioambiental com a água.

Para auxiliar nesse processo de democratização do conhecimento junto aos surdos, podemos incorporar as Tecnologias Digitais da Informação e Comunicação (TDIC), as quais combinam imagens, textos e movimentos que favorecem as interações entre sujeito-tecnologia-sujeito. De acordo com Basso ${ }^{10}$, essas tecnologias beneficiam os surdos por permitirem a comunicação em língua de sinais através de tablets e celulares, preservando, assim, a cultura surda e a Libras. Para Pinheiro e Lunardi-Lazzarin ${ }^{11}$, ao se criarem espaços virtuais educomunicativos, os internautas podem refletir e discutir com os demais usuários sobre a sua realidade socioambiental, trocando conhecimentos e produzindo novos valores e saberes. Ainda segundo as autoras ${ }^{12}$, o site YouTube, por exemplo, possui relações produtivas, já que possibilita aos surdos criarem e consumirem vídeos de outros deficientes auditivos. Segundo Guimarães ${ }^{13}$, no entanto, há poucos vídeos educomunicativos pensados e produzidos para este público, sendo que a maioria não privilegia o bilinguismo e as linguagens visuais, focando no áudio e no uso de muitos textos e legendas em português.

Ao se pesquisar e analisar a disponibilização de materiais educomunicativos de Educação Ambiental sobre as águas para surdos, observa-se poucos produtos, principalmente voltados para a educação não formal. A maior parte desses
4. MIORANDO, Tania Micheline. Formação de profissionais: mais professores para a escola sonhada. In: QUADROS, Ronice Muller de (org.). Estudos Surdos I. Petrópolis: Arara Azul, 2006. p. 76-109.

5. BRASIL. Lei $n^{\circ} 10.436$, de 24 de abril de 2002. Dispõe sobre a Língua Brasileira de Sinais - Libras e dá outras providências. Diário Oficial da União, Brasília, DF, 25 abr. 2002. Disponível em: http://www.planalto.gov.br/ ccivil_03/leis/2002/10436. htm. Acesso em: 10 set. 2017. 6. BRASIL. Decreto n ${ }^{\circ} 5.626$, de22 de dezembro de 2005 . Regulamenta a Lei $n^{\circ} 10.436$, de 24 de abril de 2002, que dispõe sobre a Língua Brasileira de Sinais - Libras, e o art. 18 da Lei $n^{\circ} 10.098$, de 19 de dezembro de 2000. Diário Oficial da União, Brasília, DF, 23 dez. 2005 Disponível em: http://www. planalto.gov.br/ccivil_03/_ Ato2004-2006/2005/Decreto/D5626.htm. Acesso em: 29 out. 2017.

7. SOUSA, Aline Nunes de. The book is not on the table: o desenvolvimento da escrita de surdos em Língua Inglesa (LE). In: QUADROS, Ronice Muller de; STUMPF, Marianne Rossi (org.). Estudos Surdos IV. Petrópolis: Arara Azul, 2009. p. 206-241.

8. BRASIL. Lei Federal $n^{\circ} 13.146$, de 6 de julho de 2015. Institui a Lei Brasileira de Inclusão da Pessoa com Deficiência (Estatuto da Pessoa com Deficiência). Diário Oficial da União, Brasília, DF, 7 jul. 2015. Disponível em: http://www.planalto. gov.br/ccivil_03/_ato20152018/2015/Lei/L13146.htm. Acesso em: 28 nov. 2017.

9. TRAJBER, Rachel. Educomunicação para coletivos educadores. In: FERRARO JÚNIOR, Luiz Antônio (coord.). Encontros e Caminhos: formação de Educadores Ambientais. Volume I. Brasília: MMA, 2005. p. 151-158. 
10. BASSO, Idavania Maria de Souza. Mídia e educação de surdos: transformações reais ou uma nova utopia? Ponto de Vista Florianópolis, n. 5, p. 113 128, 2003. Disponível em: https://periodicos.ufsc.br/ index.php/pontodevista/ article/view/1247. Acesso em: 4 abr. 2017.

11. PINHEIRO, Daiane; LUNARDI-LAZZARIN, Márcia Lise. Educação de surdos como efeito de produções culturais no contexto midiático YouTube. In: ENDIPE - ENCONTRO NACIONAL DE DIDÁTICA E PRÁTICAS DEENSINO, 16., 2012, Campinas. Anais [...]. Campinas: Unicamp, 2012. p. 2-13. Disponível em: http://endipe. pro.br/ebooks-2012/2772b. pdf. Acesso em: 11 set. 2018

\section{Ibidem}

13. GUIMARÃES, Angela Deise Santos. Leitores surdos e acessibilidade virtual mediada por tecnologias de informação e comunicação. 2009. Dissertação (Pós-graduação em Educação Profissional Tecnológica Inclusiva) Instituto Federal de Educação, Ciência e Tecnologia do estado de Mato Grosso, Cuiabá, 2009. Disponível em: http://bento. ifrs.edu.br/site/midias/arquivos/20100611100471angela_deise santos_guimaraes.pdf. Acesso em: 3 nov. 2017.

14. TEIXEIRA, Tabita; CARAMANO, Adauto. ASJA Verde: intervenção participativa de educação ambiental na ASJA - Associação dos surdos de Jaú e região. Revista Brasileira de Educação Ambiental, São Paulo, v. 12, n. 4 p. 221-241, 2017.

15. TEIXEIRA, Tabita. Material educomunicativo para o ensino de surdos: educação ambiental para as águas. 2019. Dissertação (Mestrado profissional em Ensino de Ciências Ambientais) - Escola de Engenharia de São Carlos da Universidade de São Paulo, Universidade de São Paulo, São Carlos, 2019. materiais, impressos e digitais, traduzem em Libras as versões em português, sem interatividade e com foco em crianças e jovens nas escolas. Diante dessas observações, constatou-se a necessidade em se desenvolver um material educomunicativo que englobasse a complexidade sobre as questões socioambientais relacionadas à água e auxiliasse a promoção de sua gestão compartilhada, utilizando a Libras como meio de comunicação principal para os surdos. O desenvolvimento desse produto faz parte de um mestrado profissional na área de Ensino de Ciências Ambientais.

\section{ESTUDOS REFLEXIVOS PRECEDENTES AO MATERIAL EDUCOMUNICATIVO}

Para a produção desse material educomunicativo, foram realizadas duas pesquisas prévias: (1) um estudo de caso múltiplo junto aos alunos surdos, professores e interlocutoras de Libras de uma escola estadual no município de Jaú/SP; e (2) a realização das Oficinas das Águas junto aos surdos e ouvintes da Associação dos Surdos de Jaú e Região (ASJA), dentro do projeto de Educação Ambiental ASJA VERDE (Figura 1). Cabe destacar que este projeto, gratuito e voluntário, vem sendo desenvolvido desde 2015 na Associação em parceria com o Instituto Pró-Terra, por meio de oficinas em Libras com temáticas socioambientais diversas, como pode ser observado no estudo de Teixeira ${ }^{14}$. Em 2018, as atividades trabalhadas envolveram a temática água e a sua relação natural e humana, sendo que a realização e o detalhamento dessas oficinas podem ser encontrados no trabalho da autora citada ${ }^{15}$.

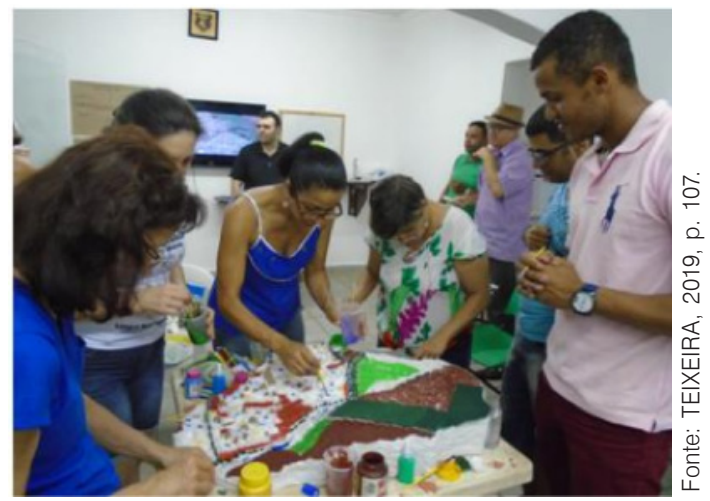

Figura 1: Atividade realizada na $2^{\text {a }}$ Oficina das Águas do projeto ASJA VERDE

Sobre os resultados obtidos: (1) o estudo de caso permitiu observar a dificuldade de acesso a conhecimentos científicos por parte dos alunos surdos, além dos poucos materiais e ferramentas disponíveis para o uso de professores e interlocutoras para com este público; (2) a pedagogia visual foi amplamente utilizada ao longo das oficinas e possibilitou a verificação do seu uso para o 
entendimento dos conteúdos e das atividades realizadas, confirmando que o tema sobre gestão compartilhada das águas pode, e deve, ser utilizado como forma de promover a Educação Ambiental, tanto para surdos quanto para os ouvintes. O uso da pedagogia visual considerou a perspectiva de Peres $^{16}$, a qual utiliza recursos visuais didáticos, como imagens, para a produção do conhecimento.

A partir da análise desses resultados, surgiram algumas reflexões sobre como o material educomunicativo poderia ser construído, sendo consenso que deveria: (1) promover a Educação Ambiental com a temática socioambiental "Água”; (2) valorizar a Libras, devendo ser acessível tanto para surdos quanto para ouvintes; (3) utilizar a pedagogia visual durante a apresentação do seu conteúdo; e (4) incorporar a TDIC para que atendesse a educação formal, não formal e informal.

Após essas reflexões, optou-se em desenvolver seis vídeos em Libras sobre gestão compartilhada das águas para serem disponibilizados posteriormente na internet, por meio do canal da ASJA no YouTube. Esse canal foi escolhido devido ao fácil acesso e por já fazer parte do nosso cotidiano, inclusive de surdos. A produção desses materiais teve como base a Lei Brasileira de Inclusão da Pessoa com Deficiência (Lei $n^{0}$ 13.146/15) e as diretrizes de comunicação e de Educação Ambiental do Conselho Nacional do Meio Ambiente (Conama Resolução $422 / 10^{17}$ ).

\section{PRODUZINDO OS VÍDEOS}

Para a produção dos vídeos, foram escolhidos seis temas principais com base no conteúdo desenvolvido ao longo das Oficinas das Águas, seus títulos são: "Água”, "Bacia hidrográfica”, "Mata ciliar", "A água que não vê", "Contaminação das águas" e "Gestão compartilhada das águas". Estes temas foram pesquisados previamente no canal do YouTube para verificar a existência, ou não, desses materiais em Libras, bem como analisar como eram abordados. Após esse levantamento, foi elaborado um roteiro em português para cada vídeo, pensando em seu conteúdo e estrutura física, nas apresentações em Libras e quais seriam os objetivos que poderiam ser alcançados ao serem visualizados. Também foram construídos slides pelo software PowerPoint contendo o conteúdo do roteiro, com pouco texto e muitas imagens e animações retiradas de sites gratuitos, principalmente pela busca de imagens do Google com filtro de licença. Tanto o roteiro quanto os slides foram revisados por técnicos da área ambiental, por professores e por uma surda oralizada que seria a apresentadora dos vídeos, ela também adaptou todo o material para a língua de sinais. Cabe destacar que durante a produção dos vídeos houve a preocupação do olhar do surdo sobre eles, para evitar o simples repasse de informações e a tradução do conteúdo em português para a Libras.

As gravações dos vídeos foram realizadas por voluntários na USP Polo de Jaú, dentro de uma sala de aula, sendo da mesma instituição os
16. PERES, Almeida. A utilização da ilustração e da imagem artística na divulgação científica para surdos. 2012. Dissertação (Mestrado em Química Biológica) - Instituto de Bioquímica Médica da Universidade Federal do Rio de Janeiro, Universidade Federal do Rio de Janeiro, Rio de Janeiro, 2012.

17. BRASIL. CONAMA. Resolução n ${ }^{\circ} 422$, de 23 de março de 2010. Estabelece diretrizes para as campanhas, ações e projetos de Educação Ambiental, conforme Lei n` 9.795, de 27 de abril de 1999, e dá outras providências. Diário Oficial da União, Brasília, DF, 24 mar. 2010. Disponível em: http://www.educadores. diaadia.pr.gov.br/arquivos/ File/educacao_ambiental/resolucao_conama_ n422_2010.pdf. Acesso em: 28 nov. 2017. 
equipamentos utilizados durante as filmagens, como uma televisão de 55 polegadas, um tripé, uma câmera digital de vídeo modelo HDR-CX240, um telão para projeção, dois notebooks, projetor e dois pendrives. Todos os equipamentos foram testados antes das gravações e o roteiro foi ensaiado previamente pela apresentadora. Por não possuir equipamentos de iluminação, as gravações foram realizadas durante o dia, com iluminação ambiente da sala. O espaço que seria filmado foi delimitado e marcado no chão com fita branca (ficando um pouco distante das paredes para não aparecerem sombras), assim como o tripé da câmera.

O cenário dos vídeos era composto por uma televisão, e a apresentadora ficava ao lado, explicando o conteúdo da temática abordada por meio dos slides que apareciam na TV, como uma vídeo-aula. A sua frente ficou uma educadora que mudava os slides com um notebook conforme o conteúdo era discutido. Optou-se por essa forma para favorecer a atuação da surda frente ao vídeo, interagindo melhor com o visualizador, uma vez que a apresentadora não estava sendo exibida numa janela de Libras no canto inferior da tela, como normalmente ocorre com os intérpretes de Libras. Além de facilitar a visualização dos sinais, esse formato possibilita que os vídeos sejam visualizados em telas menores, como os de celulares, sem prejuízo desse público. A Figura 2 ilustra o cenário no momento das gravações.



Figura 2: Gravação do $1^{\circ}$ vídeo, "Água"

8. FELS, Deborah etal Sign language online with signlink studio 2.0. In: STEPHANIDIS Constantine (ed.). Universal Access in Human-Computer Interaction. Applications and Services. Volume 5616. Berlin: Springer 2009. p. 492-501. Disponível em: https://link.springer $\mathrm{com} / \mathrm{chapter/10.1007/}$ 978-3-642-02713-0 52\#citeas. Acesso em: 11 set. 2018
A apresentadora não precisou decorar todos os roteiros, pois durante as gravações ela pôde acompanhar o conteúdo dos slides que estavam em sua frente, por meio da projeção em um telão, escritos em português. Esse método é apresentado por Fels et al. ${ }^{18}$ como Slideshow, nos outros dias um educador ficou responsável por mudar esses slides. Cabe salientar que a apresentadora não traduziu o conteúdo para a Libras no momento das gravações, ela teve a total liberdade de mudar a forma de se expressar conforme entendesse, de modo a facilitar o entendimento do visualizador. Sendo assim, o roteiro sofreu diversas alterações de seu conteúdo original no momento das filmagens, mas sem que interferisse na mensagem principal dos vídeos e nos conteúdos mais técnicos sobre a água. 
Durante as gravações, utilizou-se como técnica os videolets, proposta também por Fels et al. ${ }^{19}$, que consiste em filmar unidades menores, de, no máximo, 5 minutos, para depois emendá-las na edição final dos vídeos. Essa técnica foi pensada desde o momento da elaboração do roteiro, por isso cada slide representa um videolets, facilitando também o trabalho da apresentadora. Após as filmagens de cada vídeo, a equipe assistiu e revisou cada videolets gravado, repetindo as gravações quando havia a necessidade de refazê-los.

Para a edição final dos vídeos, e visando corrigir a iluminação ambiente, foi utilizada a versão gratuita do programa de edição Hitfilm Express e a edição geral pelo programa Movavi Video Editor. Nos vídeos, foram acrescentados créditos iniciais e as bibliografias consultadas, sendo que os logos das instituições envolvidas, apresentados nos créditos iniciais, passaram por tratamento de imagem no programa Adobe Photoshop CS6.

Para que os vídeos atendessem o público ouvinte, foram criadas legendas isoladas em português, pois, assim, o visualizador tem a opção de assistir o vídeo com ou sem legenda. Para esse processo, cada frase foi enumerada e reacolocada no vídeo com o auxílio de um arquivo do tipo "bloco de notas" (Figura 3), salvando posteriormente em extensão ".srt" (Subrip Video Subtitle Format). Esse tipo de extensão permite que as legendas isoladas não sejam gravadas junto com o vídeo e, sim, exibidas na tela quando desejado, sendo compatíveis com a maioria dos players de vídeos, como o Media Player Classic. Ressalta-se que as legendas não foram transcritas ao pé-da-letra com a Libras, mas seguindo o roteiro.

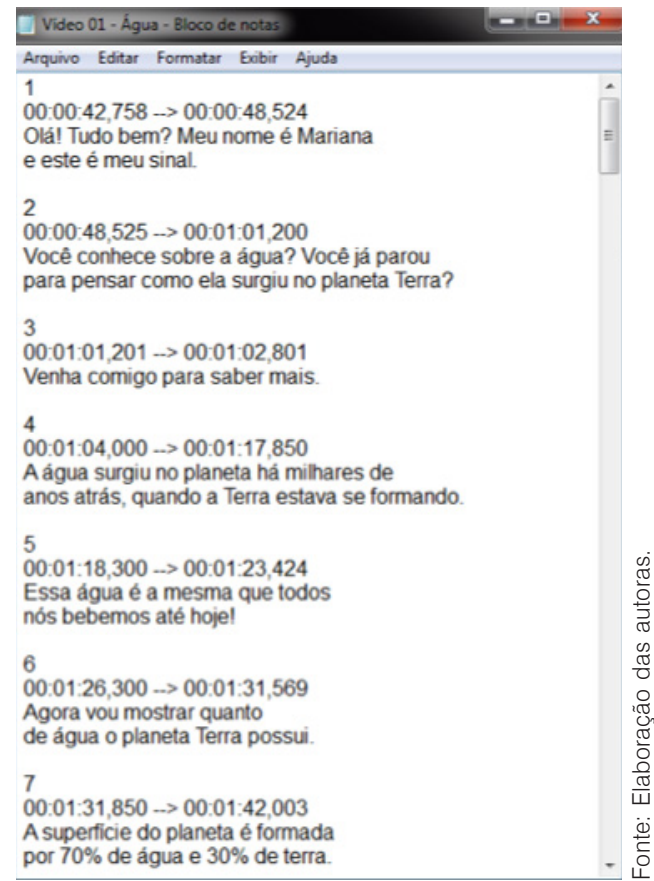

Figura 3: Exemplo de legenda salva em arquivo bloco de notas

Com os vídeos finalizados e revisados por educadores da área, esses foram postados no canal da ASJA, no YouTube, no final do mês de julho de 2019, a 
fim de divulgar o trabalho e para tornar acessível e gratuito às pessoas interessadas. No Quadro 1, são apresentados os objetivos e os conteúdos de cada vídeo.

\section{Quadro1: Objetivos e os conteúdos dos vídeos}

\begin{tabular}{|c|c|c|}
\hline & OBJETIVOS & CONTEÚDOS \\
\hline $\begin{array}{l}\text { Vídeo 1: Água } \\
\text { (11 minutos) }\end{array}$ & $\begin{array}{l}\text { Compreender a água em } \\
\text { seu estado natural e sua } \\
\text { importância para o equilíbrio } \\
\text { do planeta. }\end{array}$ & $\begin{array}{l}\text { Vídeo em Libras, trata da água em } \\
\text { seu ambiente natural, sua quantidade } \\
\text { no planeta Terra, sua composição } \\
\text { química, seus estados físicos e o } \\
\text { ciclo da água, seus benefícios para o } \\
\text { organismo humano e alterações em } \\
\text { sua composição provocadas por ações } \\
\text { antrópicas. O vídeo possui a opção de } \\
\text { legendas em português. }\end{array}$ \\
\hline $\begin{array}{l}\text { Vídeo 2: Bacia } \\
\text { hidrográfica } \\
\text { (7 minutos e } 37 \\
\text { segundos) }\end{array}$ & $\begin{array}{l}\text { Conhecer os elementos } \\
\text { de uma bacia hidrográfica } \\
\text { e compreender as suas } \\
\text { interações no espaço em que } \\
\text { está inserida. }\end{array}$ & $\begin{array}{l}\text { Vídeo em Libras, trata da composição e } \\
\text { da importância das bacias hidrográficas, } \\
\text { citando, ao final, alguns exemplos } \\
\text { encontrados no Brasil. }\end{array}$ \\
\hline $\begin{array}{l}\text { Vídeo 3: Mata } \\
\text { ciliar } \\
\text { (12 minutos e } 52 \\
\text { segundos) }\end{array}$ & $\begin{array}{l}\text { Compreender a dinâmica da } \\
\text { mata ciliar no território que } \\
\text { esta está inserida junto com } \\
\text { a fauna e flora local, além de } \\
\text { preservar a água dos rios em } \\
\text { quantidade e qualidade. }\end{array}$ & $\begin{array}{l}\text { Vídeo em Libras, trata sobre a } \\
\text { importância das matas ciliares } \\
\text { para a conservação da água e da } \\
\text { biodiversidade, além dos benefícios } \\
\text { para a sociedade humana. }\end{array}$ \\
\hline $\begin{array}{l}\text { Vídeo 4: Água que } \\
\text { não se vê } \\
\text { (10 minutos e } 32 \\
\text { segundos) }\end{array}$ & $\begin{array}{l}\text { Refletir sobre os usos da } \\
\text { água em nosso cotidiano e } \\
\text { seu consumo na produção } \\
\text { agrícola, industrial e comercial. }\end{array}$ & $\begin{array}{l}\text { Vídeo em Libras, trata sobre alguns } \\
\text { conceitos que envolvem o uso da água, } \\
\text { como os consuntivos, não consultivos } \\
\text { e a "Água invisível" ou "Água Virtual". } \\
\text { Explica também como a água é utilizada } \\
\text { na cadeia de produção de diversos } \\
\text { alimentos e materiais, refletindo no } \\
\text { papel de cada um no consumo da água. }\end{array}$ \\
\hline $\begin{array}{l}\text { Vídeo } 5: \\
\text { Contaminação das } \\
\text { águas } \\
\text { (15 minutos e } 26 \\
\text { segundos) }\end{array}$ & $\begin{array}{l}\text { Refletir sobre o descarte sem } \\
\text { tratamento de água após } \\
\text { o consumo humano e suas } \\
\text { implicações à natureza e } \\
\text { sociedade. }\end{array}$ & $\begin{array}{l}\text { Vídeo em Libras, trata sobre a } \\
\text { contaminação das águas pelas } \\
\text { atividades humanas e suas causas } \\
\text { e efeitos no meio ambiente e na } \\
\text { sociedade, além das formas de } \\
\text { captação e de tratamento de água de } \\
\text { esgoto mais comuns. }\end{array}$ \\
\hline $\begin{array}{l}\text { Vídeo 6: Gestão } \\
\text { compartilhada das } \\
\text { águas } \\
\text { (11 minutos e } 40 \\
\text { segundos) }\end{array}$ & $\begin{array}{l}\text { Conhecer algumas } \\
\text { legislações internacionais } \\
\text { e brasileiras referentes à } \\
\text { água e compreender as } \\
\text { responsabilidades, que deve } \\
\text { ser conjunta, da gestão das } \\
\text { águas entre o poder público, } \\
\text { usuários e comunidades. }\end{array}$ & $\begin{array}{l}\text { Vídeo em Libras, trata sobre os direitos } \\
\text { e deveres relacionados à água e o } \\
\text { papel de cada setor (poder público, } \\
\text { usuários e a comunidade) em sua } \\
\text { gestão. }\end{array}$ \\
\hline
\end{tabular}




\section{PROPOSTAS DE USOS DOS VÍDEOS}

Os vídeos se direcionam tanto para profissionais da área que atuam junto aos surdos, quanto para contribuir na autonomia do sujeito surdo, sendo aconselhado para pessoas a partir dos 10 anos de idade, devido à complexidade do conteúdo do vídeo 4 em diante. Destaca-se que as propostas de seu uso estão baseadas em formas de ensino e não são guias absolutos, são flexíveis para adaptação e/ou modificação a fim de atender à realidade de cada indivíduo, grupo/comunidade ou instituição, devendo ser planejada previamente para a sua efetiva utilização.

a) Ensino Formal

Complemento de aulas em escolas de Ensino Fundamental II, Ensino Médio e bilíngues (Libras e Português);

Disponibilização dos vídeos nas Salas de Recursos das escolas;

Ferramentas para estudantes de tradução e interpretação de Libras/ Língua Portuguesa e instrutores de Libras, cursos de Licenciaturas e de fonoaudiologia.

\section{b) Ensino Não Formal}

Complemento para projetos e oficinas existentes relacionados à água e aos surdos dentro das instituições;

Conscientização com associados surdos;

Ferramentas de planejamento de ações e de produção de materiais interativos em Libras com base nas temáticas.

\section{c) Ensino Informal}

Disponibilização gratuita para os internautas;

Criação de redes/grupos no Facebook e WhatsApp para discussão das temáticas e propostas de ações coletivas;

Desenvolvimento de sites e blogs que trabalhem com a temática "água" para a comunidade surda.

\section{CONSIDERAÇÕES FINAIS}

Após refletir sobre os usos dos vídeos, elaborados a partir de um estudo em conjunto com surdos de uma associação, espera-se que esse material desperte a curiosidade e estimule a avaliação crítica sobre seus conteúdos e a realidade em que seu público-alvo está inserido. Também se espera que deficientes auditivos, pesquisadores, educadores, técnicos, intérpretes e tradutores de Libras e toda a comunidade surda (incluindo familiares e amigos) possam usufruir desses produtos digitais, de forma a agregar novos conhecimentos, promovendo e partilhando a democratização das informações socioambientais relacionadas à gestão compartilhada das águas. Outra intenção é preservar e divulgar a Libras, inspirando novas ações de Educação Ambiental em 
comunidades surdas, para que estas se tornem espaços educomunicativos relacionados também ao meio ambiente.

Como continuidade desse trabalho, sugere-se que esses vídeos sejam utilizados e analisados quanto à sua aplicação e possíveis formas de interação com os surdos em espaços formais, não formais e informais de ensino, com foco na promoção da gestão compartilhada das águas.

\section{REFERÊNCIAS BIBLIOGRÁFICAS}

BASSO, Idavania Maria de Souza. Mídia e educação de surdos: transformações reais ou uma nova utopia? Ponto de Vista, Florianópolis, n. 5, p. 113-128, 2003. Disponível em: https://periodicos.ufsc.br/index.php/pontodevista/ article/view/1247. Acesso em: 4 abr. 2017.

BRASIL. Lei ${ }^{\circ}$ 9.433, de 8 de janeiro de 1997. Institui a Política Nacional de Recursos Hídricos, cria o Sistema Nacional de Gerenciamento de Recursos Hídricos, regulamenta o inciso XIX do art. 21 da Constituição Federal, e altera o art. $1^{\circ}$ da Lei $\mathrm{n}^{\circ} 8.001$, de 13 de março de 1990, que modificou a Lei $\mathrm{n}^{\circ}$ 7.990, de 28 de dezembro de 1989. Diário Oficial da União, Brasília, DF, 9 jan. 1997. Disponível em: http://www.planalto.gov.br/ccivil_03/leis/L9433. htm. Acesso em: 22 nov. 2017.

BRASIL. Lei n ${ }^{\circ} 9.795$ de 27 de abril de 1999. Dispõe sobre a educação ambiental, institui a Política Nacional de Educação Ambiental e dá outras providências. Diário Oficial da União, Brasília, DF, 28 abr. 1999. Disponível em: http:/ / www. planalto.gov.br/ccivil_03/leis/19795.htm. Acesso em: 20 jan. 2017.

BRASIL. Lei n ${ }^{\circ} 10.436$, de 24 de abril de 2002. Dispõe sobre a Língua Brasileira de Sinais - Libras e dá outras providências. Diário Oficial da União, Brasília, DF, 25 abr. 2002. Disponível em: http://www.planalto.gov.br/ccivil_03/ leis/2002/110436.htm. Acesso em: 10 set. 2017.

BRASIL. Decreto $\mathrm{n}^{\circ}$ 5.626, de 22 de dezembro de 2005. Regulamenta a Lei $\mathrm{n}^{\circ}$ 10.436, de 24 de abril de 2002, que dispõe sobre a Língua Brasileira de Sinais - Libras, e o art. 18 da Lei $\mathrm{n}^{\circ}$ 10.098, de 19 de dezembro de 2000. Diário Oficial da União, Brasília, DF, 23 dez. 2005. Disponível em: http://www.planalto.gov.br/ccivil_03/_Ato2004-2006/2005/Decreto/ D5626.htm. Acesso em: 29 out. 2017.

BRASIL. Lei Federal $n^{\circ}$ 13.146, de 6 de julho de 2015. Institui a Lei Brasileira de Inclusão da Pessoa com Deficiência (Estatuto da Pessoa com Deficiência). Diário Oficial da União, Brasília, DF, 7 jul. 2015. Disponível em: http://www.planalto.gov.br/ccivil_03/_ato2015-2018/2015/Lei/L13146. htm. Acesso em: 28 nov. 2017. 
BRASIL. Conama. Resolução $\mathrm{n}^{\circ}$ 422, de 23 de março de 2010. Estabelece diretrizes para as campanhas, ações e projetos de Educação Ambiental, conforme Lei $\mathrm{n}^{\circ}$ 9.795, de 27 de abril de 1999, e dá outras providências. Diário Oficial da União, Brasília, DF, 24 mar. 2010. Disponível em: http:/ / www.educadores.diaadia.pr.gov.br/arquivos/File/educacao_ ambiental/resolucao_conama_n422_2010.pdf. Acesso em: 28 nov. 2017.

FELS, Deborah et al. Sign language online with signlink studio 2.0. In: STEPHANIDIS, Constantine (ed.). Universal Access in Human-Computer Interaction. Applications and Services. Volume 5616. Berlin: Springer, 2009. p. 492-501. Disponível em: https:/ /link.springer.com/chapter/10.1007/9783-642-02713-0_52\#citeas. Acesso em: 11 set. 2018.

GUIMARÃES, Angela Deise Santos. Leitores surdos e acessibilidade virtual mediada por tecnologias de informação e comunicação. 2009. Dissertação (Pósgraduação em Educação Profissional Tecnológica Inclusiva) - Instituto Federal de Educação,Ciênciae Tecnologia doestadode MatoGrosso, Cuiabá,2009.Disponível em: http://bento.ifrs.edu.br/site/midias/arquivos/20100611100471angela_ deise_santos_guimaraes.pdf. Acesso em: 3 nov. 2017.

PERES, Almeida. A utilização da ilustração e da imagem artística na divulgação científica para surdos. 2012. Dissertação (Mestrado em Química Biológica) Instituto de Bioquímica Médica da Universidade Federal do Rio de Janeiro, Universidade Federal do Rio de Janeiro, Rio de Janeiro, 2012.

PINHEIRO, Daiane; LUNARDI-LAZZARIN, Márcia Lise. Educação de surdos como efeito de produções culturais no contexto midiático You Tube. In: ENDIPE - ENCONTRO NACIONAL DE DIDÁTICA E PRÁTICAS DE ENSINO, 16., 2012, Campinas. Anais [...]. Campinas: UNICAMP, 2012. p. 2-13. Disponível em: http://endipe.pro.br/ebooks-2012/2772b.pdf. Acesso em: 11 set. 2018.

MIORANDO, Tania Micheline. Formação de profissionais: mais professores para a escola sonhada. In: QUADROS, Ronice Muller de (org.). Estudos Surdos I. Petrópolis: Arara Azul, 2006. p. 76-109.

SOUSA, Aline Nunes de. The book is not on the table: o desenvolvimento da escrita de surdos em Língua Inglesa (LE). In: QUADROS, Ronice Muller de; STUMPF, Marianne Rossi (org.). Estudos Surdos IV. Petrópolis: Arara Azul, 2009. p. 206-241.

TEIXEIRA, Tabita. Material educomunicativo para o ensino de surdos: Educação Ambiental para as águas. 2019. Dissertação (Mestrado profissional em Ensino de Ciências Ambientais) - Escola de Engenharia de São Carlos da Universidade de São Paulo, Universidade de São Paulo, São Carlos, 2019. 
comunicação \& educação • Ano XXV • número 2 • jul/dez 2020

TEIXEIRA, Tabita; CARAMANO, Adauto. ASJA Verde: intervenção participativa de educação ambiental na ASJA - Associação dos surdos de Jaú e região. Revista Brasileira de Educação Ambiental, São Paulo, v. 12, n. 4, p. 221-241, 2017.

TRAJBER, Rachel. Educomunicação para coletivos educadores. In: FERRARO JÚNIOR, Luiz Antônio (coord.). Encontros e Caminhos: Formação de Educadores Ambientais. Volume I. Brasília: MMA, 2005. p. 151-158. 